\title{
Reoperation after aortocoronary bypass procedure Results in 53 patients in a group of 1041 with consecutive first operations
}

\author{
K LAIRD-MEETER, M J B M VAN DEN BRAND, P W SERRUYS, O C K M PENN, \\ M M P HAALEBOS, E BOS, P G HUGENHOLTZ \\ From University Hospital Dijkzigt, Thorax Center, Erasmus University, Rotterdam, The Netherlands
}

SUMMARY Of 1041 patients with consecutive aortocoronary bypass operations, $53(5 \cdot 1 \%)$ underwent reoperation during a mean follow-up time of three and a half years. The operative mortality of first operations was $1 \cdot 2 \%$, and of reoperations $3.8 \%$. The anatomical reason for reoperation was failure of the bypass graft in $41(77 \%)$ patients, which in 18 was accompanied by progression of disease. Progression alone was seen in seven (13\%). When symptoms occurred within six months after the first operation, failure of the bypass graft(s) was nearly always found - in 32 out of 36 instances. Progression in non-bypassed arteries was seen only when symptoms occurred later.

Late results in angina pectoris were less favourable in the group undergoing reoperation: 31 (65\%) of the 48 operated on twice and $406(46 \%)$ of the 877 patients operated on once still had angina at late follow-up. The same fraction in both groups was improved by operation: $88 \%$ versus $89 \%$.

Aortocoronary bypass surgery has become an established form of treatment in angina pectoris. Though the majority of patients feel better after operation, severe symptoms persist or recur in approximately $10 \%$ of the subjects. ${ }^{1-3}$ As time passes after the operation it might be expected that, because of progression of the disease, the number of patients with symptoms would grow. 45 Second operations in patients with persistent symptoms were performed as early as $1971 .{ }^{6}$ It has been established that such a procedure is possible with an acceptable mortality ${ }^{6-8}$; results at follow-up, however, vary. ${ }^{9-11}$ The aim of this study is to describe late results after reoperation while searching for common reasons as to why patients require this procedure. Thus, a comparison is made of preoperative vascular lesions, the extent of revascularisation at the initial operation, and of symptoms at follow-up in patients undergoing reoperation and in patients having one operation only. All patients came from the same consecutive series of aortocoronary bypass procedures carried out at one institution over a 10 year period. Furthermore, in the patients undergoing reoperation only, a relation was sought between the onset of recurrence of angina pectoris after the first operation and the presumed anatomical cause of failure of this procedure.

Accepted for publication 31 March 1983

\section{Subjects and methods}

\section{PATIENT SELECTION}

Consecutive patients undergoing single aortocoronary bypass surgery at our institution between 1971 and June 1980 constituted the study population. Indications for operation were angina pectoris despite intensive medical treatment. In 53 of the 1041 patients, symptoms necessitated reoperation before the end of 1981 at a mean interval of 24 months after the initial operation. Reoperation was generally performed by the same surgical team, except in three cases where it was carried out at another institution. The data of these three cases are included in this study.

\section{CORONARY ANGIOGRAMS}

Selective coronary angiography was performed in all patients before operation. A vessel was considered diseased when a luminal narrowing of $50 \%$ or more was seen in one of the major coronary branches or in the main stem of the left coronary artery. At recatheterisation, before the second operation, the bypass graft was injected selectively when possible. If the bypass was not opacified and if it was found to be not functioning at operation, it was considered closed. The bypass graft was considered to be failing when it was closed completely or when it was severely narrowed with a $95 \%$ or more diameter narrowing. A 
bypass was considered to be functioning when it could be opacified and did not show a narrowing of $\geqslant 95 \%$.

\section{PROGRESSION OF DISEASE}

In the native coronary arteries progression of disease was considered to have occurred when at the second catheterisation a major coronary artery showed an increase in luminal narrowing, a previously normal or less than $50 \%$ narrowed lumen showing a more than $50 \%$ lesion or a lesion of $50 \%$ or more becoming a total or subtotal occlusion. Progression could be seen in either bypassed arteries or non-bypassed arteries.

\section{REGRESSION OF DISEASE}

Regression had occurred if at the second catheterisation a totally occluded artery or a major artery with a luminal narrowing of $50 \%$ or more showed a lesion less than $50 \%$.

\section{INADEQUATE REVASCULARISATION}

Inadequate revascularisation at the primary operation was considered to have taken place when a severely narrowed major vessel could not be bypassed at first operation, when the bypass was anastomosed between two severe stenoses, or when just one graft was anastomosed to one minor branch of a diseased major coronary artery.

\section{TECHNICAL ASPECTS AT SURGERY}

At operation the aim was to bypass all severely stenosed areas in the major coronary arteries. As experience increased, more distal anastomoses were placed. In 1971 a mean of 1.33 anastomoses per patient was performed, but in 1976 there were 2.50 and in 1980 , 3.04. The saphenous vein was preferred for either single or jump grafts with multiple peripheral anastomoses. During operation, immediately after bypass was discontinued, the flow in the functioning aortocoronary vein graft was measured with an electromagnetic flow probe.

At reoperation a failing bypass was either replaced or, in the case of a local stenosis, reconstructed. If a new lesion in a major coronary artery had formed, a new graft was implanted.

\section{FOLLOW-UP}

All surviving patients were sent a questionnaire to ascertain the presence of angina pectoris or dyspnoea limiting exertion. The questionnaires were sent out in May 1981 and received up to November 1981, thus giving a follow-up time of a minimum of one year and a maximum of 10 years (mean 3.5 years).

Reoperations were included up to the end of 1981, giving a follow-up time after the second procedure of a minimum of 0.1 , a maximum of 8.5 , and a mean of 2.4 years. Follow-up data on symptoms were com- plete for the group undergoing reoperation; of those who had had only one operation, $94.4 \%$ of 929 survivors responded. Vital statistics were complete in $\mathbf{9 9 . 4 \%}$ of the patients.

\section{DATA STORAGE AND ANALYSIS}

Data were stored in MUMPS on a PDD-11 computer. Sorting and analysis were performed on a HewlettPackard 85 micro-computer. For statistical analysis the Hewlett-Packard statistical package was used (Student's $t$ test and $\chi^{2}$ contingency test).

\section{Results}

The group of 1041 patients with consecutive first operations consisted of 126 women (12\%) and 915 men $(88 \%)$. Of the 53 patients having a reoperation, four were women $(8 \%)$ and 49 were men $(92 \%)$. The mean age at first operation was slightly lower in those undergoing reoperations compared with those having had only a first operation: 49.7 , SD 6.7 years vs 52.6 , SD 7.7 years, a significant difference $(p<0.001)$. There were 12 deaths within 28 days of operation (1.2\%) and two at reoperation (3.8\%, see Table 1$)$. This difference is not significant. Late deaths were 47 or $4.5 \%$ in those undergoing only the first procedure and three or $5.7 \%$ in those undergoing the second, again not significantly different. Reoperation was infrequently undertaken in the early years of aortocoronary bypass surgery. At our institution the first was performed in 1973. In Table 2 the gradually increasing number of reoperations is shown, from one in 1973 to 15 in 1980. At the end of 1981 this resulted in a total of $53(5 \cdot 1 \%)$ of the cumulative number of first operations performed before June 1980 .

Moreover, it is evident that the percentage of patients needing a second operation decreased over the years: $7 \cdot 1 \%$ of the patients operated on before

Table 1 Deaths in total patient population subdivided into patients undergoing one and two aortocoronary bypass operations at maximum of 10 years and minimum of 1.0 year follow up

\begin{tabular}{|c|c|c|c|}
\hline & \multicolumn{2}{|l|}{ No. of patients } & \multirow{2}{*}{$\begin{array}{l}\text { No. of } \\
\text { deaths }\end{array}$} \\
\hline & $\begin{array}{l}\text { Initial } \\
\text { operation }\end{array}$ & Reoperation & \\
\hline $\begin{array}{l}\text { At first operation } \\
\text { Operative mortality } \\
\text { Late mortality }\end{array}$ & 1041 & & $\begin{array}{l}12(1.2 \%) \\
47(4.5 \%)\end{array}$ \\
\hline $\begin{array}{l}\text { At second operation } \\
\text { Operative mortality } \\
\text { Late mortality } \\
\text { Total deaths }\end{array}$ & & 53 & $\begin{array}{r}2(3.8 \%) \\
3(5 \cdot 7 \%) \\
64(6 \cdot 1 \%)\end{array}$ \\
\hline $\begin{array}{l}\text { Survivors } \\
\text { Two operations } \\
\text { Follow up data }\end{array}$ & & $\begin{array}{l}48(100 \%) \\
48(100 \%)\end{array}$ & \\
\hline $\begin{array}{l}\text { One operation } \\
\text { Follow up data }\end{array}$ & $\begin{array}{l}929(100 \%) \\
877(94 \%)\end{array}$ & & \\
\hline
\end{tabular}


Table 2 Number of aortocoronary bypass operations and reoperations performed over years

\begin{tabular}{|c|c|c|c|c|c|}
\hline \multirow[t]{2}{*}{ Year } & \multirow{2}{*}{$\frac{\text { First operation }}{\text { No. of patients }}$} & \multicolumn{4}{|l|}{ Reoperations } \\
\hline & & No. of patients & $\begin{array}{l}\text { \% of cumulative } \\
\text { first operations }\end{array}$ & Per jec & of first operation \\
\hline $\begin{array}{l}1971 \\
1972 \\
1973 \\
1974 \\
1975 \\
1976 \\
1977 \\
1978 \\
1979 \\
1980 \\
1981 \\
\text { Total }\end{array}$ & $\begin{array}{r}6 \\
27 \\
34 \\
46 \\
54 \\
114 \\
172 \\
204 \\
271 \\
113 \\
\\
1041\end{array}$ & $\begin{array}{r}-\bar{c} \\
1 \\
2 \\
4 \\
0 \\
5 \\
8 \\
14 \\
15 \\
4 \\
53\end{array}$ & $\begin{array}{l}0 \\
0 \\
1.5 \% \\
2.7 \% \\
4.2 \% \\
2.5 \% \\
2.6 \% \\
3.0 \% \\
3.7 \% \\
4.7 \% \\
5.1 \% \\
5.1 \%\end{array}$ & $\left.\begin{array}{r}2 \\
3 \\
4 \\
3 \\
3 \\
5\end{array}\right\}$ & $\begin{array}{l}(7.1 \%) \\
\\
(6.4 \%) \\
(5.4 \%) \\
(3.3 \%) \\
(1.8 \%)\end{array}$ \\
\hline
\end{tabular}

Table 3 Preoperative number of vessels diseased and number of grafts placed per patient at initial operation, for those patients having one and those having two operations

\begin{tabular}{lllll}
\hline $\begin{array}{l}\text { Vessels diseased } \\
\text { before first operation }\end{array}$ & \multicolumn{2}{l}{ One operation only } & & \multicolumn{2}{l}{ Two operations } \\
\cline { 2 - 3 } & No. of patients & Grafts per patient & No of patients \\
\hline One vessel & $179(18 \%)$ & $1 \cdot 4$ & $13(25 \%)$ & Grafts per patient \\
Two vessel & $306(31 \%)$ & $2 \cdot 3$ & $14(26 \%)$ & $1 \cdot 2$ \\
Three vessel & $423(43 \%)$ & $3 \cdot 4$ & $21(40 \%)$ & $3 \cdot 5$ \\
Left main stem disease & $80(8 \%)$ & $3 \cdot 3$ & $5(9 \%)$ & $2 \cdot 2$ \\
Total & 988 & & 53 & \\
\hline
\end{tabular}

1977 to $6.4 \%$ in 1977 and $1.8 \%$ of the patients operated on in 1980.

DATA AT FIRST OPERATION AND AT FOLLOW-UP The extent of atherosclerotic disease before operation and the number of grafts placed at the initial operation were compared in those operated on again and in those operated on only once. As can be seen in

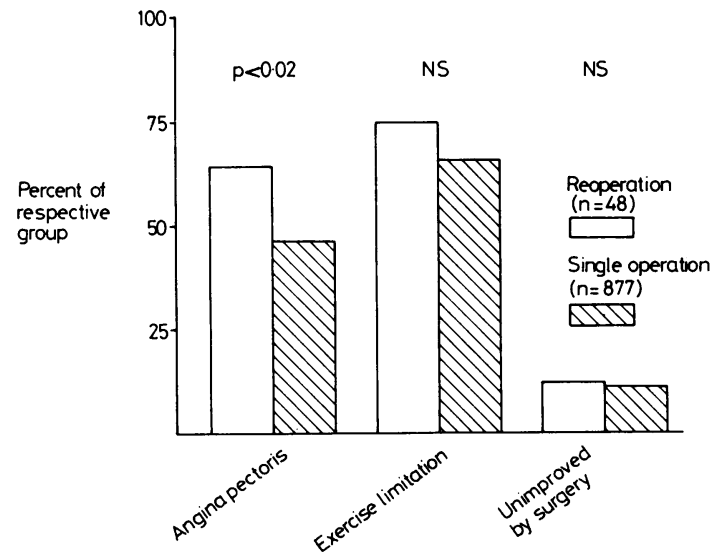

Fig. 1 Condition at late follow-up. Patients undergoing reoperation experienced angina pectoris more often, $65 \%$ vs $46 \%$ in those operated on once $(p<0.02)$. Limitation of activities by symptoms occurred in $73 \%$ vs $66 \%$ (NS) and no improvement compared with that before operation in $12 \%$ and $11 \%$, respectively $(N S)$. Follow-up time averaged 3.5 years after the initial operation.
Table 3, three vessel and left main stem disease is about equally prevalent in both groups. The number of grafts inserted per patient is also the same, except for those with left main stem disease where the number in the group operated on a second time is slightly lower: 2.2 versus 3.3 grafts per patient. This difference, however, is not statistically significant.

Angina pectoris was still experienced by 31 (65\%) of the 48 surviving patients who had reoperation, while angina pectoris was reported by $406(46 \%)$ of the 877 patients who had only a single operation. The patients operated on twice thus fared significantly worse from postoperative angina pectoris $(p<0.02)$. As can be seen in Fig. 1, dyspnoea or angina pectoris limited physical activities in 35 of $48(73 \%)$ of the patients undergoing reoperation and in 583 of 877 (66\%) of the other group; this was not, however, a significant difference. Subjective overall improvement after surgery was not different in both groups either: $88 \%$ versus $89 \%$.

The cause of recurrence of symptoms in the group undergoing reoperation, that is bypass graft failure or progression of disease, influenced late results slightly. Those with failure of bypass graft(s) fared worse in the long run than those whose symptoms could only be attributed to progression of the atherosclerotic process. In the latter category, four out of six patients $(66 \%)$ became pain free while when there was failure of the grafts (Table 4 ) only 12 out of $38(32 \%)$ became pain free. 
Table 4 Findings at recatheterisation related to time of (re)occurrence of angina pectoris after first bypass operation and incidence of symptoms at follow-up at mean of 3.5 years postoperatively

\begin{tabular}{|c|c|c|c|c|c|c|c|c|}
\hline \multirow[t]{2}{*}{$\begin{array}{l}\text { Primary finding at } \\
\text { recatheterisation }\end{array}$} & \multicolumn{5}{|c|}{$\begin{array}{l}\text { Appearance of symptoms } \\
\text { first postoperative period in months }\end{array}$} & \multirow[t]{2}{*}{$\begin{array}{l}\text { Total no. } \\
\text { of patients }\end{array}$} & \multirow[t]{2}{*}{ No. of survivors } & \multirow[t]{2}{*}{$\begin{array}{l}\text { Angina pectoris at follow-up } \\
\text { (\% of survivors) }\end{array}$} \\
\hline & 3 & $3-6$ & $6-12$ & $12-24$ & 24 & & & \\
\hline Failure of graft(s) & 16 & 4 & 2 & 1 & - & 23 & 21 & $14(67 \%)$ \\
\hline $\begin{array}{l}\text { Failure of graft(s), progression } \\
\text { bypassed artery } \\
\text { Failure of graft(s), progression } \\
\text { non-bypassed artery }\end{array}$ & 7 & $\begin{array}{r}4 \\
-\end{array}$ & - & - & $\frac{-}{2}$ & $\begin{array}{r}11 \\
2 \\
5\end{array}$ & $\begin{array}{l}10 \\
7\end{array}$ & $\begin{array}{l}6(60 \%) \\
6(86 \%)\end{array}$ \\
\hline $\begin{array}{l}\text { Graft(s) open, progression } \\
\text { bypassed artery } \\
\text { Graft(s) open, progression } \\
\text { non-bypassed artery }\end{array}$ & - & - & $\begin{array}{r}1 \\
-\end{array}$ & - & $\begin{array}{l}- \\
1 \\
3\end{array}$ & $\begin{array}{l}1 \\
1 \\
5\end{array}$ & 6 & $2(33 \%)$ \\
\hline Technical problems & 4 & - & - & - & 1 & 5 & 4 & $3(75 \%)$ \\
\hline Total & & & & & & 53 & 48 & $31(65 \%)$ \\
\hline
\end{tabular}

DATA ON GROUP UNDERGOING REOPERATION

The indication for reoperation was in all instances angina pectoris as severe or more severe in comparison with that present before the first operation. The moment of reappearance of angina pectoris in the postoperative period varied from immediately after the operation to 83 months. Of the 53 patients having a second operation, nine or $17 \%$ never lost their symptoms and by three months $53 \%$ suffered angina pectoris. At 12 months this had risen to $75 \%$. Thus, most patients who had a reoperation had symptoms in the first year after the initial operation. In Fig. 2 the cumulative percentage of patients with postoperative angina pectoris is shown versus time elapsed since the original operation. As can be seen, the increase is small but gradual from 36 months onwards.

At the time of recatheterisation (a mean of 20 months after the primary operation), 77 of the 130 inserted bypass grafts were closed, a patency rate of $59 \%$. In addition to the 77 occluded grafts, six had a luminal narrowing of $95 \%$. Thus $83(64 \%)$ of the grafts were failing, while $47(36 \%)$ could be considered to be functioning normally.

In Table 4 it is shown that of the 23 patients with bypass graft failure alone 20 had symptoms within 6 months of operation. The other frequently seen problem in patients with early symptoms was the combination of a new lesion in the bypassed artery and a failing graft. Thus, out of the 53 patients, 36 had symptoms within six months, of whom 20 had pure graft failure, and 11 had graft failure with progression in the bypassed artery, that is $86 \%$ of the patients with early symptoms. Progression of lesions in nonbypassed arteries was seen only when symptoms started later than six months after operation, except once when a combination with a failing graft was found. Exceptions to the six month cut off point of symptoms were: (a) three patients with pure graft failure and symptoms at respectively seven, seven, and 11 months; and (b) pure technical failure of the initial operation causing persistence of symptoms after operation in four patients. Twice this was because of inability to find the artery to be grafted and twice the distal anastomosis was made between two severely narrowed areas.

- Regression of disease was not seen.

\section{FLOW IN GRAFT}

At the first operation flow was measured in 127 of the 130 inserted grafts. The mean flow in the 46 grafts found later to be functioning was 56.4, SD $39 \mathrm{ml} / \mathrm{min}$, and in 81 of those found later to be non-functioning 42.3, SD $20 \mathrm{ml} / \mathrm{min}$, a significant difference $(\mathrm{p}<0.001)$.

\section{REOPERATION}

The 53 patients had their reoperation at a mean of 24.4 months after the first procedure, with a minimum of one and a maximum of 91 months. In

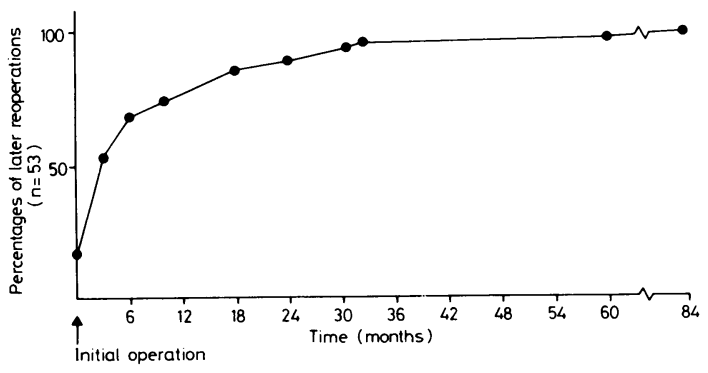

Fig. 2 Patients with postoperative angina pectoris, shown as cumulative percentage of all patients undergoing reoperation against time elapsed since the first aortocoronary bypass operation. 
total, 83 grafts had been found to be failing at recatheterisation. At the second operation 73 new grafts were inserted and a reconstruction of a severely narrowed area was performed 11 times. In two instances a stenotic aortic valve was replaced by a valve prosthesis. In all patients but one some improvement of vascularisation was obtained at operation. The one exception received a valve prosthesis.

\section{Discussion}

After the initial reports on late results of coronary bypass surgery with disappearance of angina pectoris in the large majority of patients, it was soon noticed that a small number of patients did not benefit. McNeer et al. ${ }^{12}$ reported an increase in patients experiencing angina pectoris from $38 \%$ at one year to $47 \%$ two years after operation. Campeau et al. ${ }^{13}$ in a seven year span saw an increase from $21 \%$ to $50 \%$. In both series 10 to $15 \%$ of the patients were unimproved by operation.

In the 1041 patients with consecutive operations at our institution, $47 \%$ of the survivors experienced angina pectoris at a mean follow-up time of three and a half years, and $11 \%$ of these patients had felt no better after operation. Out of this pool of 150 unimproved patients, 53 were operated on again. Selection criteria for reoperation were severe, often unstable, angina pectoris, the desire of the patient to have a second operation, and technical feasibility. The group undergoing reoperation was slightly younger than the total patient population but did not otherwise differ in preoperative number of stenosed vessels or the number of grafts placed at surgery. This is at variance with the experience of Barboriak et al. ${ }^{14}$ who noted an inadequate initial revascularisation reflected by a lower average number of bypass grafts in patients undergoing a further operation later. Their study is the only one with patients consecutively operated upon, and they also found the reoperated group to be younger.

\section{REASON FOR FAILURE OF PRIMARY OPERATION}

In our patients, failure in the function of the bypass graft(s) was the most frequently found problem at recatheterisation. Of the 53 patients, $41(77 \%)$ had failing grafts and of the 130 grafts placed at the initial operation only 47 (36\%) were functioning. This is much lower than the average patency rate at our institution of $79 \%$ at one year and $76 \%$ at three years postoperatively. ${ }^{15}$ This low patency rate could be caused by unfavourable anatomy in the distal coronary vascular bed. Such a hypothesis is supported by the fact that at operation the flow was significantly lower in the grafts later failing, $42 \mathrm{ml} / \mathrm{min}$ versus 56 $\mathrm{ml} / \mathrm{min}$ in those continuing to function. A clear cut off point, however, cannot be given, because of overlap in values.

Progression of disease in the native vessels was rare in this group: seven (13\%) patients had progression as their primary problem. It is possible, however, that this is the result of selection, as patients with extensive new changes in distal coronary arteries were not primarily selected for reoperation. Moreover, it is possible that the mean follow-up time of 3.5 years after the initial operation is not sufficiently long to see progression of disease. Loop et al. ${ }^{8}$ reported, for instance, that angina pectoris recurred a mean of 3.1 years after operation if progression was the reason for failure of the primary operation.

The fact that four $(7.5 \%)$ of our 53 patients had a purely technical reason for the inadequacy of the primary operation is regrettable, but in view of the complexity of the surgery involved, probably unavoidable. Data are scarce, but Stiles et al. ${ }^{16}$ reported inadequate first operations in $13(26 \%)$ out of 50 reoperations and Kobayashi et al. ${ }^{7}$ mention previously unbypassed lesions in 14 (29\%) of 48 patients undergoing reoperation. It is clear, however, that experience of the surgical team influences the number of reoperations, as evidenced by the decrease, from $7 \cdot 1 \%$ to $1.8 \%$ in our series over the years. The time of onset of angina pectoris after the initial operation appeared to be an indication of its cause. If angina pectoris occurred in the first six postoperative months either a malfunction of the bypass graft, with or without an occlusion in the bypassed coronary artery, or a technical failure of the primary operation, was found to be the cause. When the symptom recurred later than six months postoperatively, progression of atherosclerotic disease in the native coronary circulation was the reason. This is in accordance with the findings of Culliford $e t$ al. ${ }^{17}$ who reported an even shorter interval (two months) in which the patients with failed bypass grafts redeveloped symptoms.

The operative mortality at reoperation of $3.8 \%$ compared with $1.2 \%$ for the first operation seems acceptable. Published figures vary between $10 \%$ reported by Johnson et al. ${ }^{6}$ in 1972 and 3.7\% reported by Irarrazaval et al. ${ }^{10}$ in 1977 . Late mortality of $5.7 \%$ in 3.5 years in the group undergoing reoperation falls within that quoted in the published reports as well. ${ }^{6716}$ Late outcome in respect to angina is disappointing. Only 17 (35\%) of the 48 surviving patients were free of chest pain and only $12(25 \%)$ were completely without symptoms after two coronary bypass operations. Of those who were operated on once, the results were significantly better: $54 \%$ were free of pain and $34 \%$ were symptom free.

The low percentage of patients completely relieved of symptoms in the group undergoing reoperation has also been found by others. Kobayashi et al. ${ }^{7}$ reported 
$38 \%$ of their 79 patients to be free of angina at 12 to 70 months, Allen et al. ${ }^{18}$ described $31 \%$ of 71 patients as symptom free at a mean of 26 months, and Norwood et al. ${ }^{11}$ reported $30 \%$ of 26 patients to be free of symptoms at six to 48 months. In contrast with these results, Loop et al. ${ }^{8}$ reported that $60 \%$ of 500 patients undergoing reoperation were free of angina at an average of $\mathbf{4 0}$ months after it. As this series of reoperated patients was not part of a consecutive series of first operations, no comparison could be made.

In conclusion, reoperations after aortocoronary bypass surgery are sometimes necessary because of failure of improvement after the initial procedure. Technically the operation is feasible with a low mortality rate and few late deaths at follow-up. The cause is most often a failure of the bypass graft(s) especially when the patient develops angina within six months of operation. Though improvement in angina occurs in the majority of such patients, only one quarter become entirely free of symptoms. As the number of initial aortocoronary bypass operations is expected to increase in the coming years, it is important to realise this when advising a patient who develops angina again after a first operation.

\section{References}

1 McIntosh HD, Garcia JA. The first decade of aortocoronary bypass grafting 1967-1977. Circulation 1978; 57: 405-31.

2 European Coronary Surgery Study Group. Prospective randomised study of coronary bypass surgery in stable angina pectoris. Second interim report. Lancet 1980; ii: 491-5.

3 Lawrie GM, Morris GC Jr, Calhoon JH, et al. Clinical results of coronary bypass in 500 patients at least 10 years after operation. Circulation 1982; 66 (suppl 1): 1-5.

4 Bourassa MG, Lespẽrance J, Corbara F, Saltiel J, Campeau L. Progression of obstructive coronary artery disease 5 to 7 years after aorto coronary bypass surgery. Circulation 1978; 58 (suppl 1): 100-6.

5 Palac RT, Meadows WR, Hwang MH, Loeb HS, Pifarre $R$, Gunnar RM. Risk factors related to progressive narrowing in aorto coronary vein grafts studied 1 and 5 years after surgery. Circulation 1982; 66 (suppl 1): 40-4.

6 Johnson WD, Hoffman JF, Flemma RJ, Tector AJ. Sec- ondary surgical procedure for myocardial revascularisation. $\mathcal{F}$ Thorac Cardiovasc Surg 1972; 64: 523-9.

7 Kobayashi T, Mendez AM, Zubiate P, Vanstrom NR, Yokoyama T, Kay JH. Repeat aorto coronary bypass grafting. Chest 1978; 73: 446-9.

8 Loop FD, Cosgrove DM, Kramer JR, et al. Late clinical and arteriographic results in 500 coronary artery reoperations. F Thorac Cardiovasc Surg 1981; 81: 675-85.

9 Winkle RA, Alderman EL, Shumway NE, Harrison DC. Results of reoperation for unsuccessful coronary artery bypass surgery. Circulation 1975; 51 \& 52 (suppl 1): 61-5.

10 Irarrazaval MJ, Cosgrove DM, Loop FD, Ennix CL Jr, Groves LK, Taylor PC. Reoperations for myocardial revascularization. I Thorac Cardiovasc Surg 1977; 73: 181-8.

11 Norwood WI, Cohn LH, Collins JJ. Results of reoperation for recurrent angina pectoris. Ann Thorac Surg 1977; 23: 9-13.

12 McNeer JF, Starmer CF, Bartel AG, et al. The nature of treatment selection in coronary artery disease. Circulation 1974; 49: 606-14.

13 Campeau L, Lespẽrance J, Hermann J, Corbara F, Grondin CM, Bourassa MG. Loss of improvement of angina between 1 and 7 years after aortocoronary bypass surgery. Circulation 1975; 60 (suppl 1): 1-5.

14 Barboriak JJ, Barboriak DP, Anderson AJ, Rimm AA, Tristani FE, Flemma RJ. Risk factors in patients undergoing a second aorto-coronary bypass procedure. $\mathcal{f}$ Thorac Cardiovasc Surg 1978; 76: 111-4.

15 Brower RW, Serruys PW, Hugenholtz PG. Progression and regression of disease in the native coronary circulation and bypass grafts after coronary bypass surgery. In: Roskamm H, ed. Prognosis of coronary heart diseaseprogression of coronary arteriosclerosis. Berlin: Springer: (in press).

16 Stiles $Q R$, Lindesmith GG, Tucker BL, Hughes RK, Meyer BW. Experience with fifty repeat procedures for myocardial revascularization. $\mathcal{f}$ Thorac Cardiovasc Surg 1976; 72: 849-53.

17 Culliford AT, Girdwood RW, Isom OW, Krauss KR, Spencer FC. Angina following myocardial revascularization. $\mathcal{F}$ Thorac Cardiovasc Surg 1979; 77: 889-95.

18 Allen RH, Stinson EB, Oyer PE, Shumway NE. Predictive variables in reoperation for coronary artery disease. $\mathcal{F}$ Thorac Cardiovasc Surg 1978; 75: 186-92.

Requests for reprints to Dr Karin Laird-Meeter, Thorax Center, Erasmus University, PO Box 1738, 3000 DR Rotterdam, The Netherlands. 